Original Article

\title{
Isolation of Bacillus thuringiensis and its Insecticidal Effect against Galleria mellonella
}

\author{
${ }^{a}$ Jyoti Limbu, ${ }^{a}$ Bijay Kumar Shrestha, ${ }^{a}$ Jenish Shakya, ${ }^{b}$ Sabin Bahadur Khatri, ${ }^{a}$ Hemanta Khanal* \\ ${ }^{a}$ Department of Microbiology, Central Campus of Technology, Tribhuvan University, Dharan, Nepal \\ ${ }^{b}$ Department of Food Technology, Central Campus of Technology, Dharan, Nepal \\ *Corresponding email: khanal.hemanta@gmail.com
}

\begin{abstract}
Bacillus thuringiensis $(\mathrm{Bt})$ synthesize a large diversity of crystal proteins (Cry and Cyt) during sporulation which exhibit insecticidal activity against insects and protozoa. The main aim of this study was to isolate Bacillus thuringiensis and study its insecticidal effect against Galleria mellonella. Soil samples from four different geographical locations of Koshi Zone viz. Itahari, Tarhara, Dharan and Vedetar of Eastern Nepal were collected. The isolation of Bt was done by acetate selection method. The insect bioassay of Bt isolates were performed against greater wax moth $(G$. mellonella $)$ by feeding the third instar larvae by extracted crystal spores with three different concentrations. The overall distribution of Bt from the study sample was found to be $30 \%$ (30/100). Bt was isolated from all four geographical location with higher incidence; 9 (36\%) in Tarhara region followed by Dharan (32\%), Itahari (28\%) and Vedetar (24\%). However, the incidence of Bt with potent insecticidal activity against $G$. mellonella was reported to be $4 \%(4 / 100)$. The insecticidal activity of isolated $\mathrm{Bt}$ between test and control groups was found to be statistically significant $(\mathrm{p}<0.05)$. LC50 value of Bt from Tarhara (Tar1) was $388.29 \mu \mathrm{g} / \mathrm{mL}$, Dharan; Drn 8 and Drn1 was $416.20 \mu \mathrm{g} / \mathrm{mL}$ and $463.15 \mu \mathrm{g} / \mathrm{mL}$ respectively and from Vedetar (Vd5) was $476.63 \mu \mathrm{g} / \mathrm{mL}$. In overall study the Bt isolated from Tarhara (Tar1) region exhibited greater incidence, Bt index, efficacy and effective level of LC50 against greater wax moth. Native Bt strains isolated from soil of Eastern Nepal possess effective insecticidal activity and hence can used as biocontrol agent in controlling honeycomb pest like G. mellonella.
\end{abstract}

\author{
Article Info \\ Article history: \\ Received date: 14 September 2019 \\ Accepted date: 25 May 2020
}

Keywords:

Bacillus thuringiensis

Cry Protein

Galleria mellonella

Biopesticides

\section{Introduction}

Biological control is the most valuable tool of Integrated Pest Management (IPM) which involves the use of biological agents such as parasitoids, predators and entomopathogen like fungi, bacteria, virus nematodes etc. to control pests (Chandler et al., 2011). Bacterial biopesticide has significant attention in pest control (Sarwar, 2015). Bacillus thuringiensis (Bt) is the most commonly used and successful entomopathogenic bacterium (Jurat-Fuentes \& Jackson, 2012).

$\mathrm{Bt}$ is a gram positive, rod shaped, insecticidal bacterium which produces crystal protein called $\delta$ endotoxin during stationary phase of its growth (Kumar et al., 1996). The insecticidal property of Bt against great number of insects leads $\mathrm{Bt}$ into an important tool to be used in the insect pest management. The crystal protein produced by Bt is toxic against large number of insect species of orders Lepidoptera, Diptera, Coleoptera and few Hemiptera (MacIntosh et al., 1990). When crystal protein is ingested orally by insects, it solubilizes in the midgut which causes cell lysis and disruption of midgut epithelium leading to death. However, the presence of specific receptor in the midgut determines the toxicity of crystal protein (Bravo et al., 2007).

B. thuringiensis with different potentialities and different insecticidal effects have been observed in various part of the world. The eastern region of Nepal has a heterogeneous climate with unique geographical features and abundant biological resources (Carpenter $\&$ Zomer, 1996). Bt isolated from this region may help in finding new cry genes with potential insecticidal activity against the greater wax moth (G. mellonella) 
which is a worldwide serious honey bee pest in tropical and subtropical regions of world (Shimanuki \& Knox, 2000, Kwadha et al., 2017). PCR analysis of Bt with universal primer is specific for detection of cryl and cry2 class specific genes (Aly, 2007). Lethal Concentration 50 (LC50) is the amount of a substance required to kills $50 \%$ of a test animals exposed after a single dose. The main aim of this study was to isolate Bacillus thuringiensis from different areas of Koshi Zone and study its insecticidal efficacy against larva of greater wax moth (G. mellonella).This study was also aimed to determine Lethal Concentration 50 (LC50) of extracted crystal spore against the larva of moth.

\section{Materials and Methods}

\subsection{Research design}

This study was carried out in Central Campus of Technology Hattisar Dharan and Regional Agricultural Research Station (RARS) Tarhara from October 2018 to March 2019. Soil samples were collected from different altitudes ranging from Itahari (374 ft.), Tarhara (418 ft.), Dharan (1272 ft.) and Vedetar (5140 ft.) of Koshi Zone, Nepal. From each geographical region 25 different soil samples were collected and in total 100 different soil samples from four regions were collected. Soil samples weighing $10 \mathrm{gm}$ was collected in sterile plastic bags from $3-5 \mathrm{~cm}$ depth and transported into the laboratory at $4{ }^{\circ} \mathrm{C}$. Materials used in this experiment were Sodium acetate (HiMedia, India), Lauria Bertani (LB) broth (HiMedia, India). Nutrient Agar (HiMedia, India), Coomassie brilliant blue (HiMedia, India), Phosphate buffer saline (HiMedia, India), Grams staining reagents (HiMedia, India), MRVP medium and reagents (HiMedia, India), Indole medium (HiMedia, India), Citrate agar medium (HiMedia, India), Gelatin agar medium (HiMedia, India), Starch agar medium (HiMedia, India), Egg yolk agar medium (HiMedia, India), Blood agar medium (HiMedia, India), Carbohydrate fermentation broth (HiMedia, India), SIM medium (HiMedia, India), Triple sugar iron agar (HiMedia, India).

\subsection{Isolation and identification of Bacillus thuringiensis}

B. thuringiensis was isolated by Acetate selection method as described by Travers et al. (1987) with slight modification. One gram of soil sample was taken in a sterile conical flask containing $1 \mathrm{~mL}$ of $0.25 \mathrm{M}$ sodium acetate (pH 6.8) and $9 \mathrm{~mL}$ of Lauria Bertani (LB) broth (HiMedia, India). The broth was incubated for overnight at $30^{\circ} \mathrm{C}$. After incubation the broth was heated at $100^{\circ} \mathrm{C}$ for 5 minute. After heat treatment, $0.1 \mathrm{~mL}$ of sample was taken and spread on nutrient agar (HiMedia, India) and plates were incubated at $30^{\circ} \mathrm{C}$ for overnight. Bt like colonies white, large, nearly circular with fine irregular margins and may be glossy, less glossy or rough were selected and further sub cultured on nutrient agar (HiMedia, India). Bt was further identified by routine microbiological tests like Gram's staining and other biochemical tests like indole test, MR test, VP test, citrate test, starch test, gelatin test, beta haemolysis test, sucrose, fructose, mannitol, lactose fermentation test, motility test and lecithinase test after incubation of the culture in the respective biochemical test media (Sneath, 1986). For presence of parasporal crystal staining the bacterial culture incubated for 72 hours in a nutrient broth was used. Smear was stained with $0.25 \%$ coomassie brilliant blue for 3 minutes and washed with distilled water and observed under light microscope at oil immersion (Muniady et al., 2011). The bacteria were identified as Bacillus thuringiensis based on colony morphology, Gram's staining, biochemical test and parasporal body staining. In this study B. thuringiensis DOR Bt-1 strain was used as a positive control.

\subsection{Rearing of greater Wax Moth G. mellonella}

The greater wax moth Glleria mellonella was obtained from Department of Entomology, Regional Agricultural Research Station (RARS) Tarhara and reared in the laboratory according to Mohamed and Coppel, (1983). Artificial diet for moth comprised following ingredients:- Deionized, preboiled water $100 \mathrm{~mL}$, Honey, commercial brand $-150 \mathrm{~mL}$, Bee wax - 3gm, Cholesterol - 1gm, Multivitamin supplement $4 \mathrm{~mL}$, Maize flour - 100gm, Milk powder - 100gm.

Adult wax moths were kept into 1litre mason jars where the mating took place. Folded sheets of wax with paper clips were placed where the moth deposited eggs. The eggs were removed and transferred into the $500 \mathrm{~mL}$ Mason jar with $150 \mathrm{gm}$ of medium and incubated at $28.5^{\circ} \mathrm{C}$ in the dark. After 10-15 days second instar larvae appeared. After 8-10 days larvae were transferred into 1liter Mason jar with 175gram of medium. Within 5-10 days third instar larvae became available which were used for insect bioassay.

\subsection{Preparation of mass culture of Bacillus thuringiensis}

The mass culture of $\mathrm{Bt}$ was prepared as described 
by Ammouneh et al. (2011). Lauria Berteni (LB) broth was used for the preparation of mass culture of Bt. Pure culture of $\mathrm{Bt}$ was inoculated in sterile $\mathrm{LB}$ broth and incubated in water bath shaker at $25^{\circ} \mathrm{C}$ for 4 days. Spores were harvested by centrifugation at $10000 \mathrm{rpm}$ for 15 minutes. Pellets were washed twice with sterile distilled water. Cell disruption process was done by lyophilization. Lyophilized powder was dried in laminar air flow and later it was stored at $-20^{\circ} \mathrm{C}$ until use.

\subsection{Insect bioassay}

Insect Bioassay was performed according to Ammouneh et al. (2011). Bt preparation (spore/protein mixture) in the form of powder was used for bioassay. Three different concentrations $(1000 \mu \mathrm{g} / \mathrm{mL}, 500 \mu \mathrm{g} / \mathrm{mL}$ and $250 \mu \mathrm{g} / \mathrm{mL}$ ) of spore/protein mixture were prepared in phosphate buffer saline (PBS: $1 \mathrm{M} \mathrm{KH}_{2} \mathrm{PO}_{4}, 1 \mathrm{M}$ $\left.\mathrm{K}_{2} \mathrm{HPO}_{4}, 5 \mathrm{M} \mathrm{NaCl}, \mathrm{pH}-7.2\right)$. Third instar larvae were used for the bioassay. About $0.5 \mathrm{~mL}$ of each concentration was mixed with 1 gram of larval food and placed in disposable plastic cups (30mm diameter). For each dose three replicates were prepared with 5 larvae in each replicate. As a negative control, the artificial diet was supplemented with sterile $0.5 \mathrm{~mL}$ distilled water. The cups were covered with muslin cloth and wrapped with rubber band. Hence in total, 45 larvae for each $\mathrm{Bt}$ isolate were taken under study. Larvae were put into an empty box for 2 hours to starve before releasing them for treatment. Dead and live record of bioassay was recorded every day until pupation.

\subsection{Data analysis}

Data recorded from bioassay was documented and tabulated in MS-EXCEL 2010. The statistical analysis for calculating LC50 values of each treatment were performed according to Stephan (1977) from concentration-mortality curves. The data were statistically analyzed by SPSS version 16.0 windows software. Statistical significance was established when $\mathrm{p}$ value was less than equal to 0.05 with $95 \%$ confidence interval.

\section{Results and Discussion}

\subsection{Distribution of Bt in soil}

The overall distribution of $\mathrm{Bt}$ from the study sample was found to be $30 \%$ (30/100). The number of $\mathrm{Bt}$ isolates from Itahari, Tarhara, Dharan and Vedetar were $7(28 \%), 9(36 \%), 8(32 \%)$ and $6(24 \%)$ respectively (Fig. 1).

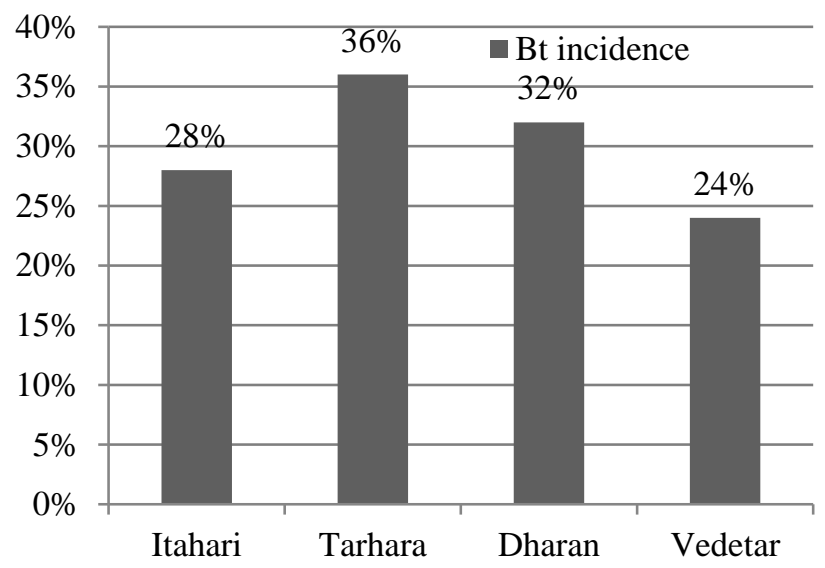

Fig. 1: Bt isolates from sampling area

\subsection{Bt index}

Bt index is defined as the ratio of number of identified $\mathrm{Bt}$ colonies to the total number of sporeforming bacilli colonies. Bt was calculated according to Alvarez \& del Valle Loto, (2012). The highest Bt index was found to be 0.16 from Tarhara and least index of 0.12 from Vedetar (Fig. 2).

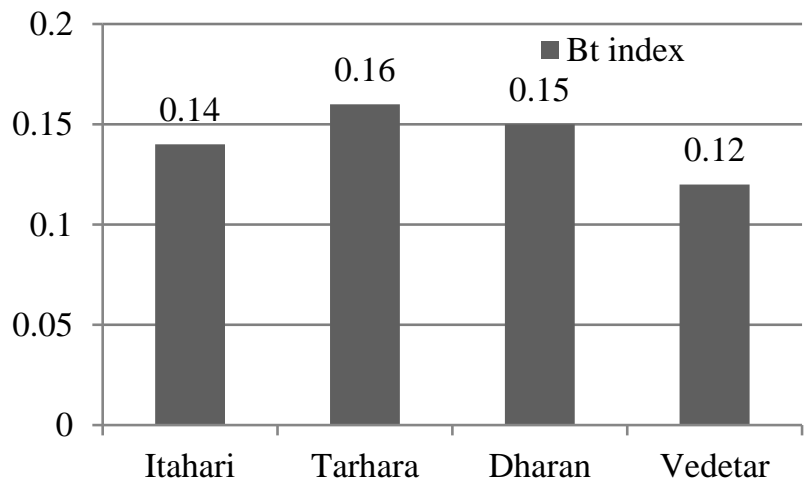

Fig. 2: Bt index

\subsection{Distribution of Potent Bt isolates}

Bt isolates were obtained from soil samples of different areas of various altitudes where none of these areas had been previously treated with isolation of $\mathrm{Bt}$. After acetate selection (Travers et al., 1987) of 100 soil samples from 4 different areas (Itahari, Tarhara, Dharan and Vedetar), 30 (30\%) Bt isolates were obtained. Among 30 isolates only 4 (4\%) isolates showed an insecticidal activity against greater wax moth (G. mellonella) and remaining 26 (96\%) were negative. Potent isolates were recovered from all study areas except from Itahari; the isolate Tar1 was isolated from Tarhara, Drn8 and Drn1 from Dharan and Vd5 from Vedetar (Fig. 3). 
Table 1: Insect Bioassay. For each concentration treatment 15 larvae were taken under study that required 45 larvae for study in all three concentrations. Cn-Concentrations. Tar1-Tarhara1, Drn8-Dharan8, Drn1-Dharan1, Vd5-Vedetar5

\begin{tabular}{|c|c|c|c|c|c|c|c|}
\hline Treatment & $\begin{array}{c}\text { Total larva used } \\
\text { in all } 3 \mathrm{Cn} \\
\end{array}$ & $\begin{array}{c}\text { Total Deaths at } \\
1000 \mu \mathrm{g} / \mathrm{mL}\end{array}$ & $\begin{array}{c}\mathbf{p} \\
\text { value }\end{array}$ & $\begin{array}{r}\text { Total Deaths } \\
\text { at } 500 \mu \mathrm{g} / \mathrm{mL} \\
\end{array}$ & $\begin{array}{c}\mathbf{p} \\
\text { value }\end{array}$ & $\begin{array}{l}\text { Total Deaths } \\
\text { at } 250 \mu \mathrm{g} / \mathrm{mL}\end{array}$ & $\begin{array}{c}\mathbf{p} \\
\text { value }\end{array}$ \\
\hline Positive Control & 45 & 14 & & 12 & & 8 & \\
\hline Negative Control & 45 & 0 & & 0 & & 0 & \\
\hline Tar1 & 45 & 14 & & 9 & & 5 & \\
\hline Drn8 & 45 & 9 & & 5 & & 3 & \\
\hline Drn1 & 45 & 9 & $\mathrm{P}<0.05$ & 4 & $\mathrm{P}<0.05$ & 2 & $P>0.05$ \\
\hline $\mathrm{Vd} 5$ & 45 & 10 & & 4 & & 2 & \\
\hline
\end{tabular}

Table 2: Efficacy \% of Bt isolates

\begin{tabular}{lcccc}
\hline Treatment & Efficacy \% & \% survival & \% Mortality by all Bt isolates & p value \\
\hline Positive control & 75.55 & 24.45 & - & - \\
Negative control & 0.00 & 100.00 & - & - \\
Tar1 & 62.22 & 37.78 & & P \\
Drn8 & 37.78 & 62.22 & $42.22 \%$ & \\
Drn1 & 33.33 & 66.67 & & \\
Vd5 & 35.56 & 64.44 & & \\
\hline
\end{tabular}

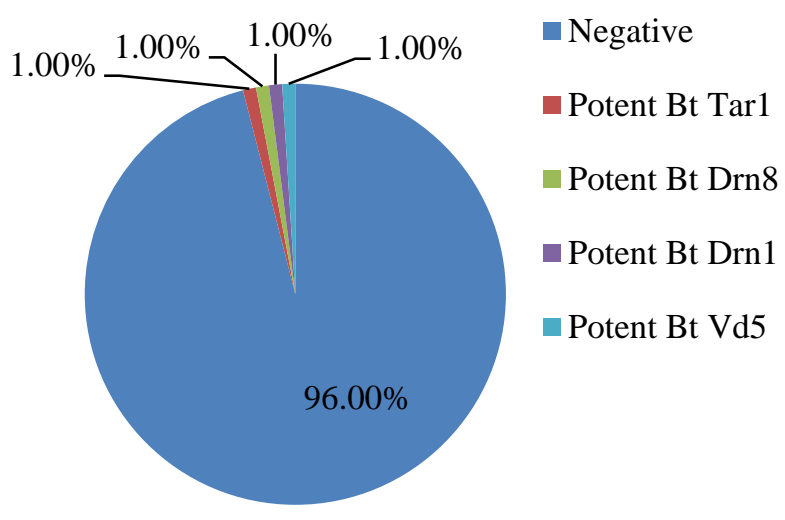

Fig. 3: Distribution of Potent Bt isolates

\subsection{Insect bioassay}

Three different concentrations $(1000 \mu \mathrm{g} / \mathrm{mL}$, $500 \mu \mathrm{g} / \mathrm{mL}$ and $250 \mu \mathrm{g} / \mathrm{mL}$ ) of spore/crystal were maintained for insect Bioassay. Dead and live record of bioassay was recorded every day until pupation (Table 1).

\subsection{Efficacy of Bt isolates}

Efficacy \% of $\mathrm{Bt}$ isolates were calculated by modified Abbott, (1925). In this study Tar1 exhibited greater efficacy against greater wax moth (62.22\%) whereas Drn 1 exhibited least efficacy $(33.33 \%$ ) (Table 2).

\subsection{LC50 of Bt}

The dose mortality response of G. mellonella at different concentrations of spore/crystal mixture of $\mathrm{Bt}$ isolates LC50 value was calculated (Table 3).
Table 3: LC50 of Bt

\begin{tabular}{lccll}
\hline Bt isolate & Tar1 & Drn8 & Drn1 & Vd5 \\
\hline LC50 value & 388.29 & 416.20 & 463.15 & 476.63 \\
\hline *All measurements in $\mu \mathrm{g} / \mathrm{mL}$
\end{tabular}

The entomopathogenic activity of Bacillus thuringiensis has made it widely used successful biopesticide. Since, Nepal is an agriculture country the use of this biopesticide in agriculture will be ecofriendly and effective approach. Variable percentage of B. thuringiensis was found depending on their origin, $28 \%$ in Itahari, $36 \%$ in Tarhara, 32\% in Dharan and $24 \%$ in Vedetar. Rana et al. (2002) reported only $0.022 \%$ of $\mathrm{Bt}$ isolates obtained from soil samples from far-western, mid-western, western, central and eastern regions of Nepal which is relatively less in comparison to this study. Ohba et al. (2002) reported that the frequency of $\mathrm{Bt}$ positive soil samples averaged between $9.5 \%$ and $16.9 \%$ in the oceanic islands of Japan, which are in agreement with the general percentages obtained from this study. Nepal has a wide diversity in ecosystem and biological resources that forms the bedrock for variation in the distribution of beneficial microorganism in soil. The isolated native $\mathrm{Bt}$ is considered as the indigenous microflora of the soil. However, its commercial use in developing nation like Nepal in pest management has rarely being applied.

Selection of $\mathrm{Bt}$ was attempted by eliminating germinated cells through $5 \mathrm{~min}$ of heat treatment at $100^{\circ} \mathrm{C}$. This modification was effective for selective 
isolation of Bacillus thuringiensis from other bacillus species. This experiment with modification was based on the fact that acetate inhibits the germination of $\mathrm{Bt}$ spores allowing it to resist heat treatment which will allow for its selective isolation from other spore forming and non-spore forming organisms which will germinate on medium during incubation but would be killed in heat treatment (Rana et al., 2002). In earlier reports varying values of $\mathrm{Bt}$ index were frequently reported in several studies which ranged from 0.009 to 0.380 in soil samples of India (Thaphan et al., 2008). Ramalakshmi \& Udayasuriyan (2010) reported 0.034 to $0.055 \mathrm{Bt}$ index in samples of Western Ghats, India. Bt index of 0.2 to 0.5 was observed in sample from New Zealand (Chilcott \& Wigley, 1993). Shishir et al. (2014) reported 0.86 Bt index in their samples from Bangladesh. The studies reported diversity in Bt index in different areas across the world. In this study, higher Bt index was found in Tarhara which was 0.16 followed by Dharan and Itahari with 0.15 and 0.14 respectively. Least $\mathrm{Bt}$ index was found in Vedetar which was 0.12. Vilas-Bo \& Lemos (2004) suggested the $\mathrm{Bt}$ index may be an outcome of the biotic environmental factor, e.g., the vegetation type, the type of insect commonly found in the area, or microorganism in the soil, besides, abiotic factors such as the nutrient availability, texture, $\mathrm{pH}$, temperature and humidity. These factors could be the reason behind variation of Bt index in these study Zones.

In this study 30 isolates from 100 soil samples were confirmed to be B. thuringiensis based on staining, biochemical tests and coomassie brilliant blue staining (CBBS) technique although the morphology of the bacteria differed from the sample site. In this study the coomassie brilliant blue staining (CBBS) of 72 hours old culture revealed centrally located parasporal body. The parasporal body (crystal protein) is made of protein compound which can be well stained by coomassie brilliant blue as dark blue color where the spore remain unstained and the vegetative cell gets light blue stain (Ammons et al., 2002). The presence of crystal protein in $\mathrm{Bt}$ isolates from our sample site indicates that soil of Eastern Nepal is rich in diversity of potent Bt strains.

The greater wax moth, G. mellonella Linnaeus has been identified as a serious pest against Honey bee. Larvae are mostly found in old combs of honey bees, feeding on beeswax, wax residues of honey, insect skin and pollen (Shimanuki \& Knox, 1991). The larvae of the wax moth cause considerable damage to unattended combs by bees and to combs in storage (Caron, 1992). In this study the Bioassay of Bt against greater wax moth was performed for both qualitative and quantitative study. A series of bioassays were performed by providing the food contaminating with the spores and crystals. Spores and crystals were both included in the suspensions because they produced a higher level of mortality than either crystals or spores alone (Crickmore, 2006). Qualitative bioassay results showed $42.22 \%$ of mortality by all Bt isolates tested to Galleria melllonella larva. Chilcott \& Wigley (1993) showed that the percentage of isolates obtained from soil with toxicity against lepidopteran larvae ranged from $37 \%$ to $88 \%$. Similarly, Iriarte et al. (1998) reported that most of the $\mathrm{Bt}$ isolates showed insecticidal activity (above $25 \%$ mortality) against some lepidopteran species. In this study Bt isolates showed $33.33 \%$ to $62.22 \%$ mortality which is consistent with the previous reports. $B t$ isolated from Tarhara showed high degree of mortality which indicates that soil of Tarhara area harbors potent strains of Bt. The soil of Tarhara which has been used for organic agricultural practices might have contributed in ecological maintenance of native strains of potent $\mathrm{Bt}$. The insecticidal activity of isolated Bt among test and control groups was found to be statistically significant $(\mathrm{p}<0.05)$.

Three different concentration of spore/protein mixture $(1000 \mu \mathrm{g} / \mathrm{mL}, 500 \mu \mathrm{g} / \mathrm{mL}$, and $250 \mu \mathrm{g} / \mathrm{mL})$ were used for bioassay. Among all isolates Tar1 was the most potent which showed $62.22 \%$ efficacy followed by Drn8 and Vd5 which is $37.78 \%$ and $35.56 \%$ respectively. B. thuringiensis isolated from Drn1 showed least efficacy which was $33.33 \%$. This difference may be due to ecological environment which was not highly selective as of high altitude region and also may be due to various agricultural and industrial practices, which could not be explained from the present study. The Bioassay of $\mathrm{Bt}$ protein at concentration of $1000 \mu \mathrm{g} / \mathrm{mL}$ reported significant mortality of greater wax moth which was statistically significant $(\mathrm{p}<0.05)$. Similar statistical significance was observed even with Bt protein mixture with concentration of $500 \mu \mathrm{g} / \mathrm{mL}$. However, the insect bioassay with $250 \mu \mathrm{g} / \mathrm{mL}$ was not statistically significant with test and control group $(p>0.05)$. There was statistical difference in mortality of greater wax moth by isolated $\mathrm{Bt}$ at three different concentrations 
$(\mathrm{p}<0.05)$. Hence, it is reported that the level of toxins also determined the mortality of insect. LC50 value of the tested isolates against $G$. mellonella larvae varied from 388.29 to $476.63 \mu \mathrm{g} / \mathrm{mL}$. It is reported that, toxicity of Bacillus thuringiensis depends upon the size and abundance of crystal protein found in the bacteria (Rana et al., 2002). So, this might be the reason behind various toxicity levels among different isolates. In overall analysis the Bt isolated from Tarhara exhibited grater incidence, $\mathrm{Bt}$ index, efficacy against greater wax moth and effective level of LC50. Further studies are needed to understand the role of ecological environment and soil composition that harbors potent Bt strains from soil of Tarhara region of Koshi Nepal.

\section{Conclusions}

The study revealed that the soil of eastern Nepal holds wide diversity of native Bt strains. The diversity in cry protein content and insecticidal activity might have relationship with geographical location and environment. From this study it is also concluded that $B$. thuringiensis is a safe microbial agent for controlling greater wax moth (G. mellonella) and it can be used in the development of bio insecticides to control pests. The mass production, formulation and rational use of $\mathrm{Bt}$ as biopesticide can assist in eliminating agricultural pests and hence can prevent the environmental hazards caused by use of chemical pesticides.

\section{Acknowledgments}

The authors acknowledge all the supporting hands of Department of microbiology, Central Campus of Technology, Dharan.

\section{Conflicts of Interest}

The authors declare no conflicts of interest.

\section{Funding}

This research received no funds.

\section{References}

Abbott, W. S. (1925). A Method of computing the effectiveness of an insecticide. Journal of Economic Entomology, 18(2): 265-267.

Alvarez, A., \& del Valle Loto, F. (2012). Characterization and biological activity of Bacillus thuringiensis isolates that are potentially useful in insect pest control. Biodiversity Enrichment in a Diverse World, 133.
Aly, N. A. (2007). PCR detection of cry genes in local Bacillus thuringiensis isolates. Australian Journal of Basic and Applied Sciences, 1(4), 461-466.

Ammons, D., Rampersad, J., \& Khan, A. (2002). Usefulness of staining parasporal bodies when screening for Bacillus thuringiensis. Journal of invertebrate pathology (Print), 79(3), 203-204.

Ammouneh, H., Harba, M., Idris, E., \& Makee, H. (2011). Isolation and characterization of native Bacillus thuringiensis isolates from Syrian soil and testing of their insecticidal activities against some insect pests. Turkish Journal of Agriculture and Forestry, 35(4), 421-431.

Bravo, A., Gill, S. S., \& Soberón, M. (2007). Mode of action of Bacillus thuringiensis Cry and Cyt toxins and their potential for insect control. Toxicon, 49(4), 423-435.

Caron, D. M. (1992) Wax moth. American Bee Journal, 132(10), 647-649.

Carpenter, C., \& Zomer, R. (1996). Forest ecology of the Makalu-Barun National Park and Conservation Area, Nepal. Mountain Research and Development, 135-148.

Chandler, D., Bailey, A. S., Tatchell, G. M., Davidson, G., Greaves, J., \& Grant, W. P. (2011). The development, regulation and use of biopesticides for integrated pest management. Philosophical Transactions of the Royal Society B: Biological Sciences, 366(1573), 1987-1998.

Chilcott, C. N., \& Wigley, P. J. (1993). Isolation and toxicity of Bacillus thuringiensis from soil and insect habitats in New Zealand. Journal of Invertebrate Pathology, 61(3), 244-247.

Crickmore, N. (2006). Beyond the spore-past and future developments of Bacillus thuringiensis as a biopesticide. Journal of Applied Microbiology, 101(3), 616-619.

Iriarte, J., Bel, Y., Ferrandis, M. D., Andrew, R., Murillo, J., Ferré, J., \& Caballero, P. (1998). Environmental distribution and diversity of Bacillus thuringiensis in Spain. Systematic and applied microbiology, 21(1), 97-106.

Jurat-Fuentes, J. L., \& Jackson, T. A. (2012). Bacterial entomopathogens. In Insect pathology (pp. 265349). Academic Press. 
Kumar, P. A., Sharma, R. P., \& Malik, V. S. (1996). The insecticidal proteins of Bacillus thuringiensis. Advances in Applied Microbiology, 42, 1-43.

Kwadha, C. A., Ong'amo, G. O., Ndegwa, P. N., Raina, S. K., \& Fombong, A. T. (2017). The biology and control of the greater wax moth, G. mellonella. Insects, 8(2), 61 .

MacIntosh, S. C., Stone, T. B., Sims, S. R., Hunst, P. L., Greenplate, J. T., Marrone, P. G., ... \& Fuchs, R. L. (1990). Specificity and efficacy of purified Bacillus thuringiensis proteins against agronomically important insects. Journal of invertebrate pathology, 56(2), 258-266.

Mohamed, M. A., \& Coppel, H. C. (1983). Mass rearing of the greater wax moth, G. mellonella (Lepidoptera: Pyralidae), for small-scale laboratory studies. The Great Lakes Entomologist, 16(4), 7.

Muniady, S., Rathinam, X., \& Subramaniam, S. (2011). Quick isolation and characterization for the confirmation of a novel Bacillus thuringiensis strains from chicken manure samples. African Journal of Microbiology Research, 5(20), 31313137.

Ohba, M., Tsuchiyama, A., Shisa, N., Nakashima, K., Lee, D. H., Ohgushi, A., \& Wasano, N. (2002). Naturally occurring Bacillus thuringiensis in oceanic islands of Japan, Daito-shoto and Ogasawara-shoto. Applied Entomology and Zoology, 37(3), 477-480.

Ramalakshmi, A., \& Udayasuriyan, V. (2010). Diversity of Bacillus thuringiensis isolated from western ghats of Tamil Nadu state, India. Current microbiology, 61(1), 13-18.

Rana, P., Sijapat, J., Rana, N., \& Regmi, C. (2002). Distribution of Bacillus thuringiensis in the Soils of
Nepal and Their Bioassay. Nepal Journal of Science and Technology, 4(1).

Sarwar, M. (2015). Biopesticides: an effective and environmental friendly insect-pests inhibitor line of action. International Journal of Engineering and Advanced Research Technology, 1(2), 10-15.

Shimanuki, H., \& Knox, D. A. (1991). Diagnosis of honey bee diseases. Agriculture Handbook, Agricultural Research Service, US Department of Agriculture, (690).

Shishir, A., Roy, A., Islam, N., Rahman, A., Khan, S. N., \& Hoq, M. (2014). Abundance and diversity of Bacillus thuringiensis in Bangladesh and their cry genes profile. Frontiers in Environmental Science, 2,20 .

Sneath, P. H. (1986). Endospore-forming Grampositive rods and cocci. Bergey's manual of systematic bacteriology, 2, 1104-1207.

Stephan, C. E. (1977). Methods for calculating an LC 50. In Aquatic toxicology and hazard evaluation. ASTM International.

Thaphan, P., Keawsompong, S., \& Chanpaisaeng, J. (2008). Isolation, toxicity and detection of cry gene in Bacillus thuringiensis isolates in Krabi province, Thailand. Songklanakarin Journal of Science \& Technology, 30(5).

Travers, R. S., Martin, P. A., \& Reichelderfer, C. F. (1987). Selective process for efficient isolation of soil Bacillus spp. Applied and Environmental Microbiology, 53(6), 1263-1266.

Vilas-Bôas, G. T., \& Lemos, M. V. F. (2004). Diversity of cry genes and genetic characterization of Bacillus thuringiensis isolated from Brazil. Canadian journal of microbiology, 50(8), 605-613.

How to cite: Limbu, J., Shrestha, B. K., Shakya, J., Khatri, S. B., \& Khanal, H. (2020) Isolation of Bacillus thuringiensis and its Insecticidal Effect against Galleria mellonella. Himalayan Journal of Science and Technology, 3-4, 96-102. 